\title{
Unintentional incorporation of hydrogen in wurtzite InN with different surface orientations
}

\author{
Vanya Darakchieva, K Lorenz, Mengyao Xie, E Alves, C L Hsiao, L C Chen, \\ L W Tu, W J Schaff, T Yamaguchi and Y Nanishi
}

\section{Linköping University Post Print}

N.B.: When citing this work, cite the original article.

Original Publication:

Vanya Darakchieva, K Lorenz, Mengyao Xie, E Alves, C L Hsiao, L C Chen, L W Tu, W J Schaff, T Yamaguchi and Y Nanishi, Unintentional incorporation of hydrogen in wurtzite InN with different surface orientations, 2011, Journal of Applied Physics, (110), 6, 063535.

http://dx.doi.org/10.1063/1.3642969

Copyright: American Institute of Physics (AIP) http://www.aip.org/

Postprint available at: Linköping University Electronic Press

http://urn.kb.se/resolve?urn=urn:nbn:se:liu:diva-71796 


\title{
Unintentional incorporation of hydrogen in wurtzite InN with different surface orientations
}

\author{
V. Darakchieva, ${ }^{1,2, a)}$ K. Lorenz, ${ }^{2}$ M.-Y. Xie, ${ }^{1}$ E. Alves, ${ }^{2}$ C. L. Hsiao, ${ }^{3}$ L. C. Chen, ${ }^{3}$ L. W. Tu, ${ }^{4}$ \\ W. J. Schaff, ${ }^{5}$ T. Yamaguchi, ${ }^{6}$ and Y. Nanishi ${ }^{6}$ \\ ${ }^{1}$ Department of Physics, Chemistry and Biology, Linköping University, Linköping SE-58183, Sweden \\ ${ }^{2}$ Instituto Tecnológico e Nuclear, 2686-953 Sacavém and CFNUL, Lisbon 1649-003, Portugal \\ ${ }^{3}$ Center for Condensed Matter Sciences, National Taiwan University, Taipei 106, Taiwan \\ ${ }^{4}$ Department of Physics and Center for Nanoscience and Nanotechnology, National Sun Yat-Sen University, \\ Kaohsiung 80424, Taiwan \\ ${ }^{5}$ Department of Electrical and Computer Engineering, Cornell University, Ithaca, New York 14853, USA \\ ${ }^{6}$ Department of Photonics, Ritsumeikan University, Shiga 525-8577, Japan
}

(Received 23 May 2011; accepted 18 August 2011; published online 30 September 2011)

\begin{abstract}
We have studied hydrogen impurities and related structural properties in state-of-the-art wurtzite InN films with polar, nonpolar, and semipolar surface orientations. The effects of thermal annealing and chemical treatment on the incorporation and stability of $\mathrm{H}$ are also discussed. The near-surface and bulk hydrogen concentrations in the as-grown films increase when changing the

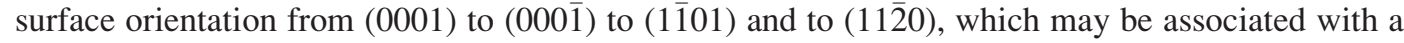
decrease in the grain size and change of the growth mode from $2 \mathrm{D}$ to $3 \mathrm{D}$. Thermal annealing at $350{ }^{\circ} \mathrm{C}$ in $\mathrm{N}_{2}$ leads to a reduction of $\mathrm{H}$ concentrations and the intrinsic levels of bulk $\mathrm{H}$ are found to correlate with the structural quality and defects in the annealed films. (C) 2011 American Institute of Physics. [doi:10.1063/1.3642969]
\end{abstract}

\section{INTRODUCTION}

InN is a material of substantial contemporary interest for high speed electronics and when alloyed with GaN or AlN for solar cell and optoelectronic devices. The growth of InN epitaxial layers with good structural quality and free electron concentrations in the range $10^{17}-10^{18} \mathrm{~cm}^{-3}$ has led to significant progress in our understanding of the material properties and the physical mechanisms behind them. ${ }^{1}$ However, control of the unintentional $n$-type conductivity in InN has not been achieved yet. Hydrogen is one of the major sources of doping in InN. ${ }^{2-10}$ Recently, it has been shown that hydrogen is ubiquitous and can be found in significant concentrations in $c$-plane InN films grown by molecular beam epitaxy (MBE). ${ }^{2,5-7,9}$ However, nothing is known about the unintentional incorporation of hydrogen in $\mathrm{InN}$ films with surface orientations different from the conventional $c$-plane. This issue is particularly important in view of the generally higher free electron concentrations observed in nonpolar InN films compared to polar material. Furthermore, there is a strong research interest in growing $\mathrm{InN}$ and related alloys with nonpolar and semipolar orientations to avoid or minimize the effects of the polarization fields in device heterostructures and enable efficient green and white light emitting diodes. ${ }^{11}$

In this work, we report a study on the unintentional incorporation of hydrogen in MBE InN with (0001), (0001), (1101), and (1120) surface orientations. The effects of thermal annealing and chemical treatment on the bulk and nearsurface $\mathrm{H}$ concentrations are also investigated. The results

\footnotetext{
a) Author to whom correspondence should be addressed. Electronic addresses: vanya@ifm.liu.se and vanya@itn.pt.
}

are discussed in view of the structural and morphological properties of the films.

\section{EXPERIMENTAL}

Several sets of state-of-the-art InN films grown by MBE at National Sun Yat-Sen University and National Taiwan University (set I), ${ }^{12,13}$ Ritsumeikan University (sets II and III), ${ }^{14-16}$ and Cornell University (set IV) ${ }^{17,18}$ were studied. Each set of samples included an $a$-plane and either an In- or a N-polar InN films. Set I also included a semipolar InN film and set II included an $m$-plane InN sample. The N-polar films were grown directly on sapphire, low-temperature (LT) InN buffer layers, or in situ $\mathrm{GaN}$ buffer layer. The In-polar films were grown with GaN buffer layers. Details on the nucleation scheme and respective references are listed in Table I. The free electron concentrations in the $c$-plane films vary from $2 \times 10^{17} \mathrm{~cm}^{-3}$ to $6 \times 10^{18} \mathrm{~cm}^{-3}$ and the sets included several films with low $10^{17} \mathrm{~cm}^{-3}$ electron concentrations and mobilities up to $2000 \mathrm{~cm}^{2} / \mathrm{V}$.s. The $a$-plane and semipolar films have free electron concentrations in the range $10^{18}-10^{19} \mathrm{~cm}^{-3}$ and optical mobilities up to $580 \mathrm{~cm}^{2} /$ V.s., whereas the $m$-plane film exhibits free electron concentration in the mid- $10^{19} \mathrm{~cm}^{-3}$ range and mobility of $200 \mathrm{~cm}^{2}$ / V.s. Further details on the free electron and structural properties of the InN films can be found in Refs. 5, 9, 19, and 20.

The presence of hydrogen impurities was investigated by $2 \mathrm{MeV}^{4} \mathrm{He}^{+}$elastic recoil detection analysis (ERDA) at $12^{\circ}$ incidence with the surface of the sample. The Si surface barrier detector was located at a $24^{\circ}$ scattering angle, so the outgoing angle is also $12^{\circ}$. The set-up was used with two different types of stopping foils: a $10-\mu \mathrm{m}$ Kapton and 8- $\mu \mathrm{m}$ aluminum foil. Full experimental details are given elsewhere. ${ }^{21}$ 
TABLE I. Summary of the buffer layers, thickness, $d$ and respective references for further details on growth and properties of the InN films with different surface orientations.

\begin{tabular}{|c|c|c|c|c|c|c|c|c|c|c|c|c|}
\hline \multirow[b]{2}{*}{ Samples } & \multicolumn{3}{|c|}{ Set I } & \multicolumn{3}{|c|}{ Set II } & \multicolumn{3}{|c|}{ Set III } & \multicolumn{3}{|c|}{ Set IV } \\
\hline & Buffer & $\mathrm{d}(\mathrm{nm})$ & Ref. & Buffer & $\mathrm{d}(\mathrm{nm})$ & Ref. & Buffer & $\mathrm{d}(\mathrm{nm})$ & Ref. & Buffer & $\mathrm{d}(\mathrm{nm})$ & Ref. \\
\hline (0001) & In situ $\mathrm{GaN}$ & 1270 & 9,12 & - & - & - & $\mathrm{GaN}$ & 750 & 16,20 & $\mathrm{GaN}$ & 1600 & 9,17 \\
\hline$(000 \overline{1})$ & MOVPE InN & 1280 & 9,12 & LT InN & 360 & 9,14 & - & - & - & - & - & - \\
\hline$(000 \overline{1})$ & - & - & - & LT InN & 420 & 9,14 & - & - & - & - & - & - \\
\hline$(10 \overline{1} 1)$ & Nitridation & 370 & 13,20 & - & - & - & - & - & - & - & - & - \\
\hline$(1 \overline{1} 00)$ & - & - & - & None & 400 & 16,20 & - & - & - & - & - & - \\
\hline$(11 \overline{2} 0)$ & Nitridation & 695 & 13,20 & Nitridation & 513 & 15,20 & LT InN & 500 & 16,20 & $\mathrm{GaN}$ & 827 & 18 \\
\hline
\end{tabular}

To obtain the $\mathrm{H}$ concentrations in the films, the ERDA data were fitted with the NDF code using background correction models for double scattering and pile-up. ${ }^{22} \mathrm{~A}$ value of 6.81 $\mathrm{g} \mathrm{cm}^{-3}$ was used for the bulk density of InN to determine the $\mathrm{H}$ depth profiles. All samples were measured in several sample spots to improve the accuracy of the results and the $\mathrm{H}$ concentrations extracted from the fits were averaged. The structural quality of the films was assessed by Rutherford backscattering/channeling (RBS/C) spectrometry.

$\mathrm{X}$-ray diffraction rocking curve $(\mathrm{RC})$ measurements were performed using monochromated $\mathrm{Cu} \mathrm{K} \alpha_{1}$ radiation on a D8Discover system from Bruker-AXS. A Göbel mirror and an asymmetric two-bounce $\mathrm{Ge}(220)$ monochromator were used on the primary side and a scintillation detector was employed on the secondary side. The RCs were acquired with an open detector without slits or analyzer in the secondary beam.

Scanning electron microscopy (SEM) was performed with electron beam accelerating energy of $10 \mathrm{kV}$ in a Leo 1500 Gemini SEM (Oxford Research Instruments). A Veeco DI CP-II atomic force microscope was used for the topographic characterization. The rms roughness of the samples was measured on $5 \times 5 \mu \mathrm{m}^{2}$ areas.

\section{RESULTS AND DISCUSSION}

Figure 1(a) shows representative experimental ERDA spectra and the fits to the data for set I of InN films with different surface orientations. The respective $\mathrm{H}$ depth profiles obtained from the experimental data are shown in Fig. 1(b). A significant enhancement of the $\mathrm{H}$ concentration is observed at high energies, i.e., in the near-surface regions of all films [Figs. 1(a) and 1(b)].

The resulting averaged near-surface $\mathrm{H}$ areal densities $(\mathrm{H}$ atoms $/ \mathrm{cm}^{2}$ ) and bulk $\mathrm{H}$ concentrations (at. \%) for the same set of samples are shown with filled symbols in Figs. 2(a) and 2(b), respectively. Both near-surface and bulk $\mathrm{H}$ concentrations in the as-grown films show a similar trend of increasing when changing the surface orientation from In-polar to $\mathrm{N}$-polar to semipolar (1101) to nonpolar $a$-plane. The bulkand near-surface $\mathrm{H}$ concentrations, and the respective standard errors of the mean for all samples are given in Table II. The errors are indicative for the lateral homogeneity of the $\mathrm{H}$ concentrations. Higher bulk- and near-surface $\mathrm{H}$ concentrations in the $a$-plane films is observed for all sets (Table II).
Also independently of the sample set, the N-polar films exhibit generally higher $\mathrm{H}$ concentrations compared to the In-polar case.

In general, crystallographic orientation has a strong impact on impurity and dopant incorporation in IIInitrides. ${ }^{23}$ For instance, it is well known that $\mathrm{N}$-polar GaN tends to incorporate higher impurity concentrations compared to Ga-polar material. $\mathrm{H}$ on the substitutional $\mathrm{N}$ site, which is one of the donor sites in InN, ${ }^{3}$ bonds to one In atom at the (0001) surface and to three In atoms at the $(000 \overline{1})$ surface. Therefore, better sticking and thus higher concentrations of $\mathrm{H}$ may be expected for the N-polar-oriented $\mathrm{InN}$. We measured higher bulk $\mathrm{H}$ concentrations in the $\mathrm{N}$-polar films in comparison to the In-polar samples [see Table II and Fig. 2(b)]. However, it is difficult to draw a firm conclusion because other factors like $\mathrm{N}$ to In ratio also influence the incorporation of impurities. Previously, it was shown that under N-rich conditions, the impurities incorporate at much higher levels as compared to the In-droplet case and $\mathrm{O}$ becomes the dominant impurity species for In-polar InN. ${ }^{7}$ Regarding the $a$-plane surfaces, $\mathrm{H}_{\mathrm{N}}$ bonds to three In atoms,
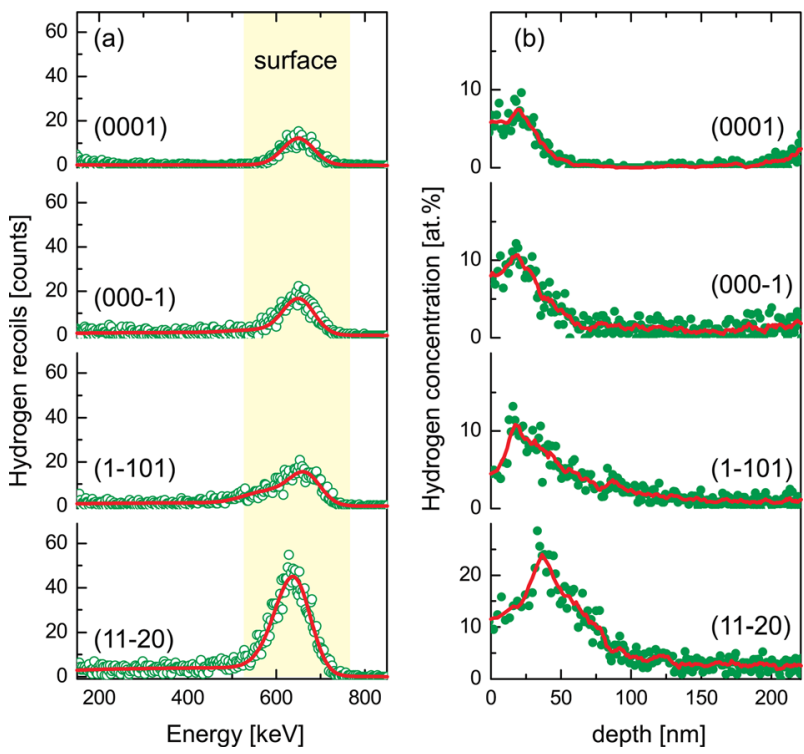

FIG. 1. (Color online) (a) Experimental (symbols) and fitted (lines) ERDA hydrogen spectra, and (b) hydrogen depth profiles extracted from the data of four representative samples (set I, see Table II) with different orientations indicated above each spectrum. 


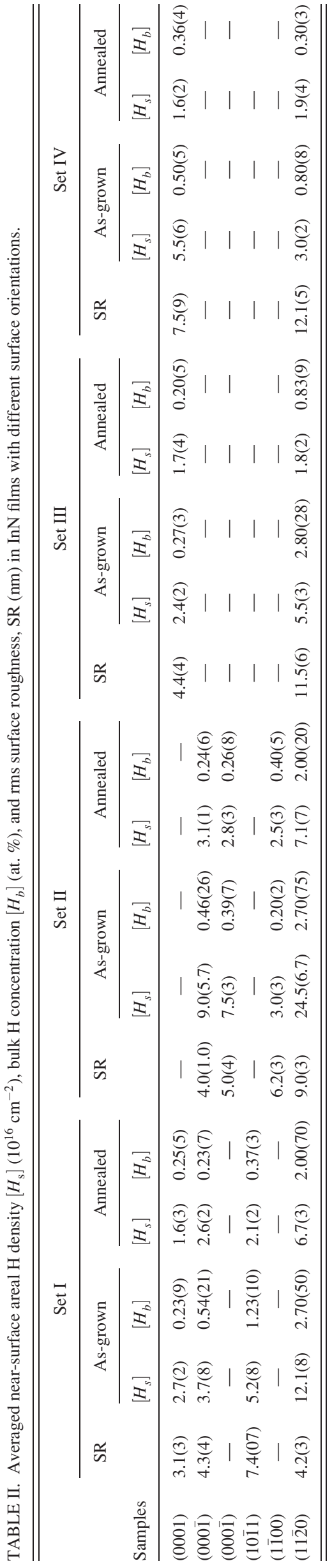

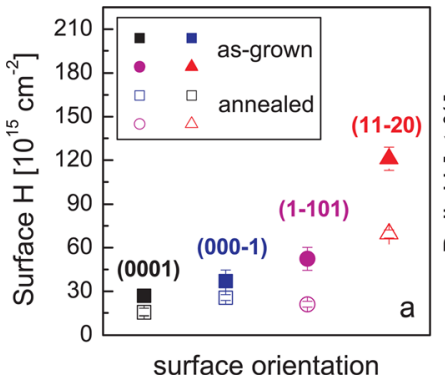

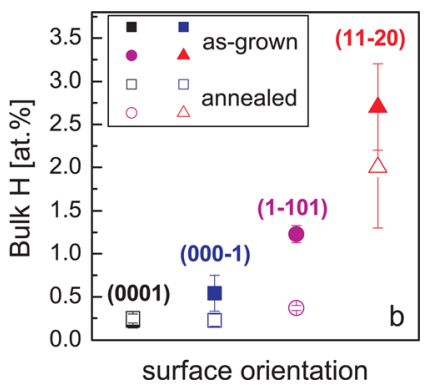

FIG. 2. (Color online) (a) Near-surface $H$ areal density $H_{s}$, and (b) bulk $H$ concentration $\mathrm{H}_{\mathrm{b}}$ of the $\mathrm{InN}$ films from set I. Filled and open symbols indicate the as-grown and annealed samples, respectively.

similarly to the N-polar case, and one may expect similar incorporation of $\mathrm{H}$ in terms of sticking. However, much higher $\mathrm{H}$ concentrations are measured in the as-grown $a$ plane samples compared to the (0001) oriented InN films (Table II).

The surface orientation has a strong effect on structural characteristics and surface morphology, ${ }^{9,20}$ which can in turn affect the incorporation of $\mathrm{H}$. Figure 3 shows SEM images of the four representative $\mathrm{InN}$ films with different orientations (set I). The In-polar InN film is completely coalesced indicating 2D growth [Fig. 3(a)], whereas the N-polar film exhibits grain structure with relatively large grain size with diameters of $0.5-1.0 \mu \mathrm{m}$ [Fig. 3(b)]. In both cases, the cplane InN films were grown on GaN buffer layers. The semipolar [Fig. 3(c)] and nonpolar InN [Fig. 3(d)] grow in a 3D fashion, and the grain size is much smaller in the latter case. These results, supported by similar observations in all sets of samples, suggest that the smaller the grain size the higher the amount of $\mathrm{H}$ in the as-grown sample. For instance, the $m$ plane $\mathrm{InN}$ showing quasi $2 \mathrm{D}$ growth has very little $\mathrm{H}$ (similar to the In-polar films) compared to the $a$-plane and semipolar films (Table II) with smaller grain sizes. Regarding the nearsurface $\mathrm{H}$, it is only natural to find more $\mathrm{H}$ in films with a smaller grain size as the surface area available to accommodate $\mathrm{H}$ is larger in such instances. Our observation of higher bulk $\mathrm{H}$ concentrations in the films with smaller grain sizes indicates that $\mathrm{H}$ may be residing along grain boundaries rather than actually being incorporated into the bulk. In this respect, we mention that the bulk $\mathrm{H}$ concentrations in our films exceed the free electron concentrations by one to two orders of magnitude implying large amounts of electrically inactive $\mathrm{H}$. The degree by which the bulk $\mathrm{H}$ exceeds the free electron concentrations is much higher for the nonpolar InN, which is consistent with the scenario of electrically inactive $\mathrm{H}$ residing on grain boundaries. Previously, $\mathrm{H}$ concentrations exceeding, although scaling with, the free electron concentrations in $c$-plane InN films have been also reported. ${ }^{7,9}$

Another factor that may affect the incorporation of $\mathrm{H}$ in the near surface region is the surface roughness. The values of the rms surface roughness of all InN samples are given in Table II. The rms surface roughness varies between $3.1 \mathrm{~nm}$ and $7.5 \mathrm{~nm}$ for the as-grown $c$-plane InN films. A comparison between the In-polar films shows a higher near-surface $\mathrm{H}$ concentration in the rougher as-grown film. Note that in these cases the surface morphologies of the films revealed $2 \mathrm{D}$ growth mode. It was shown previously that a higher 


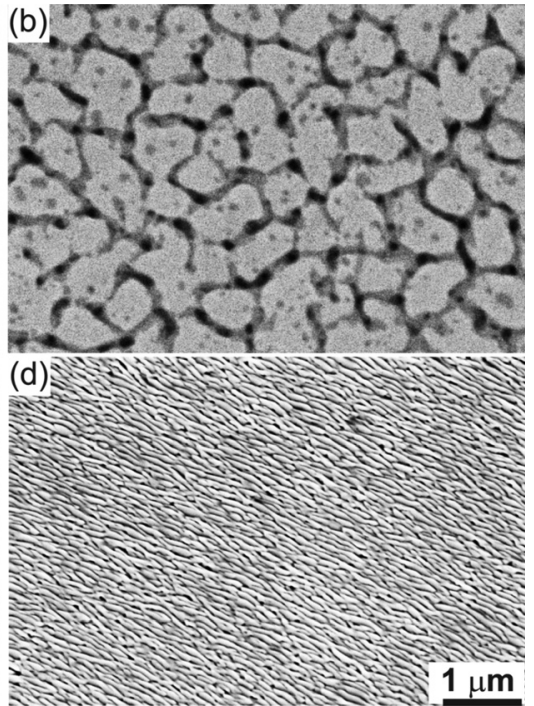

FIG. 3. Scanning electron micrographs of the same $\mathrm{InN}$ films (set I) as in Fig. 2: (a) (0001) oriented InN, (b) (0001) oriented InN, (c) (1101) oriented InN, and (d) (1120) oriented InN. The scale bar in (d) refers to all micrographs. concentration of near-surface $\mathrm{H}$ in $c$-plane $\mathrm{AlGaN} / \mathrm{GaN}$ heterostructures can be associated with a higher surface roughness. $^{24}$ In the latter, the amount of $\mathrm{H}$ was quantified by nuclear reaction analysis, which allows the measurement of high-resolution depth profiles. ${ }^{24}$ In our semipolar and nonpolar InN films, exhibiting 3D growth mode, the rms surface roughness varies between $4.2 \mathrm{~nm}$ and $12.1 \mathrm{~nm}$ (see Table II). No apparent correlation with the amount of near-surface $\mathrm{H}$ and surface roughness could be inferred for these films.

Interestingly, we found that treatment of $\mathrm{InN}$ films with common degreasing chemicals such as $\mathrm{C}_{2} \mathrm{H}_{3} \mathrm{OH}$ (methanol), $\mathrm{C}_{2} \mathrm{H}_{5} \mathrm{OH}$ (ethanol), $\left(\mathrm{CH}_{3}\right)_{2} \mathrm{CHOH}$ (isopropanol) and $\left(\mathrm{CH}_{3}\right)_{2} \mathrm{CO}$ (acetone), may lead to significant enhancement of the near-surface and bulk $\mathrm{H}$. This is especially well pronounced for the $a$-plane $\mathrm{InN}$ films and also indicates that $\mathrm{H}$ diffuses along grain boundaries already at room temperature. For instance, the $\mathrm{H}$ concentrations in the $a$-plane $\mathrm{InN}$ film from set I increase upon chemical treatment up to 8.8 at. \% for the bulk and to $4 \times 10^{17} \mathrm{~cm}^{-2}$ in the near-surface region. In some occasions, simple exposure to ambient atmosphere has also led to a slight increase in the $\mathrm{H}$ concentrations in the $a$ plane films. Theoretical calculations have shown that exposure of InN nonpolar surfaces to humidity results in spontaneous dissociation of water to $\mathrm{H}$ and $\mathrm{OH}^{25}$ The same work further reports that organic compounds including methanol also dissociate exothermically at the nonpolar InN surfaces; in all cases, $\mathrm{H}$ bonds to the $\mathrm{N}$ dangling bonds. We note that in the ERDA experiments we measure the total amount of $\mathrm{H}$ independently of its form: atomic, molecular, or in the form of complexes.

To investigate the intrinsic incorporation and stability of $\mathrm{H}$ in the films, we preformed thermal annealing at $350^{\circ} \mathrm{C}$ in $\mathrm{N}_{2}$ for $15 \mathrm{~h}$ and measured the $\mathrm{H}$ concentrations in the annealed films. The thermal annealing results in a decrease of the bulk- and near-surface H concentrations in all samples except the $m$-plane InN (Table II). However, the structural characterization indicates deterioration of the crystal quality of this sample. In contrast, a slight improvement of the structural characteristics upon annealing is typically observed in the rest of the samples. In addition, the size of the m-plane
InN sample is very small allowing only single measurement of the $\mathrm{H}$ concentration. We also note that the $\mathrm{H}$ introduced during the chemical treatment of our InN films can be completely removed upon thermal annealing. Despite the reduction of $\mathrm{H}$ concentrations upon annealing a substantial part of $\mathrm{H}$ remains still trapped inside the annealed $\mathrm{InN}$ films. First principle calculations have shown that interstitial $\mathrm{H}$ and substitutional $\mathrm{H}$ on the $\mathrm{N}$ site (the two donor sites of $\mathrm{H}$ in $\mathrm{InN}$ ) become mobile at $100{ }^{\circ} \mathrm{C}$ and $300{ }^{\circ} \mathrm{C}$, respectively. ${ }^{3}$ The strong band bending at the surface of $\mathrm{InN}$ associated with the surface electron accumulation creates a potential barrier for the positively charged $\mathrm{H}$ donors. Consequently, significant concentrations of $\mathrm{H}$ remain in the bulk of the material even after annealing. The intrinsic bulk $\mathrm{H}$ concentrations in our annealed films are higher than the respective free electron concentrations. This indicates that still a large portion of the trapped $\mathrm{H}$ is electrically inactive, most probably in the form of complexes that are tightly bound to the lattice.

The results for the bulk and surface $\mathrm{H}$ concentrations in the annealed InN films with different surface orientations from the representative set I are shown with open symbols in Figs. 2(a) and 2(b). The annealed polar and semipolar films show similar concentrations of $\mathrm{H}$ in the bulk and in the near-surface regions. This supports the suggestion that the observed differences in the $\mathrm{H}$ levels in the as-grown (0001), (000) $)$, and (1101) InN films are most probably a result of different concentrations of $\mathrm{H}$ residing on grain boundaries. It further indicates that the crystallographic orientation is not the dominant factor determining the $\mathrm{H}$ concentrations in these cases. Indeed, we find that the intrinsic bulk $\mathrm{H}$ concentrations scale with the densities of edge type dislocations in the annealed N-polar films.

The amount of $\mathrm{H}$ in the $a$-plane InN films from sets I, II, and III still remains higher compared to the films with (0001), (000 $\overline{1})$, and (1 $\overline{1} 01)$ surface orientations (Table II). On the other hand, the annealed $a$-plane film from set IV has bulk $\mathrm{H}$ concentration that is very similar to the intrinsic levels in the polar films. In order to get further insight into the 




FIG. 4. (Color online) Bulk $\mathrm{H}$ concentration, $\mathrm{H}_{\mathrm{b}}$ vs the minimum yield along $\langle 11 \overline{2} 0\rangle, \chi_{\min }$ (triangles), and vs the on-axis (112̄0) RC anisotropy (inverted triangles) for the $a$-plane InN films.

reason for the observed different behavior in the annealed aplane samples we studied in more detail the structural properties of the films.

A good measure of the overall structural quality of epitaxial films is the minimum yield, $\chi_{\min }$ measured by RBS/C, which is the ratio between the yield in the aligned spectrum taken along a certain crystallographic direction and the random yield. The minimum yield is not only sensitive to extended defects [as x-ray diffraction rocking curves (RC), for example] but also to the presence of native point defects, in particular In interstitials. A comparison between the different $a$-plane InN films shows that the bulk $\mathrm{H}$ concentration decreases with decreasing minimum yield along the main $\langle 11 \overline{2} 0\rangle$ axis (Fig. 4). In fact, the $a$-plane InN with the lowest $\chi_{\min }$ of $5.8 \%$ has a bulk $\mathrm{H}$ concentration as low as 0.3 at. \%, which is comparable to the respective concentrations in polar InN films (Table II). This indicates that the structural quality and defects play a more important role than the crystallographic orientation for the $\mathrm{H}$ incorporation into the $\mathrm{InN}$ lattice. We found that the higher the (1120) RC widths and anisotropy the higher the bulk $\mathrm{H}$ concentration in the $a$-plane films (Fig. 4). The RC anisotropy was estimated as the ratio between the RC FWHM along the [1100] and [0001], respectively. ${ }^{20}$ The broadening of the on-axis RCs is affected by the presence of screw component dislocations in the films. On the other hand, no correlation could be seen between the $\mathrm{H}$ concentrations and the (1100) RC widths, which are sensitive to the presence of basal stacking faults (BSFs). BSFs are inside the grains with no contact to the surface whereas dislocations propagate to the surface and often are distributed along grain boundaries. Our findings indicate that $\mathrm{H}$ does not diffuse in large amounts inside the grains or does not get trapped by BSFs.

\section{CONCLUSIONS}

In summary, as-grown InN films show increasing incorporation of $\mathrm{H}$ in the bulk and near-surface regions when changing the surface orientation from In-polar to $\mathrm{N}$-polar to
$(1 \overline{1} 01)$ to $(11 \overline{2} 0)$, which may be associated with a decrease in the grain size and change of growth mode from 2D to 3D. Thermal annealing at $350{ }^{\circ} \mathrm{C}$ in $\mathrm{N}_{2}$ leads to a reduction in the bulk and near-surface $\mathrm{H}$ concentrations. As a result, polar and semipolar InN films show similar levels of $\mathrm{H}$ whereas the $\mathrm{H}$ concentrations in the $a$-plane $\mathrm{InN}$ still remain relatively higher in most of the cases. Our results suggest that a substantial part of the unintentionally incorporated $\mathrm{H}$ in asgrown InN reside on grain boundaries and it is most probably electrically inactive. A comparison between different films with $a$-plane surface orientations indicates that the intrinsic $\mathrm{H}$ concentrations correlate with the minimum yield and the on-axis RC widths and anisotropy. We conclude that defects, grain size, and growth mode play more important roles for the unintentional incorporation of $\mathrm{H}$ in $\mathrm{InN}$ than the crystallographic orientation.

\section{ACKNOWLEDGMENTS}

This work is financially supported by FCT Portugal under contract PTDC/FIS/100448/2008 and program Ciência 2007, and by the Swedish Research Council (VR) under grant No.2010-3848.

${ }^{1}$ Indium Nitride and Related Alloys, edited by T. D. Veal, C. F. McConville, and W. J. Schaff (CRC Press, Boca Raton, 2009).

${ }^{2}$ D. C. Look, H. Lu, W. Schaff, J. Jasinski, and Z. Liliental-Weber, Appl. Phys. Lett. 80, 258 (2002).

${ }^{3}$ A. Janotti and C. G. Van de Walle, Appl. Phys. Lett. 92, 032104 (2008).

${ }^{4}$ G. Pettinari, F. Masia, M. Capizzi, A. Polimeni, M. Losurdo, G. Bruno, T. H. Kim, S. Choi, A. Brown, V. Lebedev, V. Cimalla, and O. Ambacher, Phys. Rev. B 77, 125207 (2008).

${ }^{5}$ V. Darakchieva, T. Hofmann, M. Schubert, B. E. Sernelius, B. Monemar, P. O. A. Persson, F. Giuliani, E. Alves, H. Lu, and W. J. Schaff, Appl. Phys. Lett. 94, 022109 (2009).

${ }^{6}$ V. Darakchieva, N. P. Barradas, M.-Y. Xie, K. Lorenz, E. Alves, M. Schubert, P. O. A. Persson, F. Giuliani, F. Munnik, C. L. Hsiao, L. W. Tu, and W. J. Schaff, Physica B 44, 4476 (2009).

${ }^{7}$ C. S. Gallinat, G. Koblmüller, and J. S. Speck, Appl. Phys. Lett. 95, 022103 (2009).

${ }^{8}$ S. Ruffenach, M. Moret, O. Briot, and B. Gil, Appl. Phys. Lett. 95, 042102 (2009).

${ }^{9}$ V. Darakchieva, K. Lorenz, N. P. Barradas, E. Alves, B. Monemar, M. Schubert, N. Franco, C. L. Hsiao, W. J. Schaff, L. W. Tu, T. Yamaguchi, and Y. Nanishi, Appl. Phys. Lett. 96, 081907 (2010).

${ }^{10}$ V. Darakchieva, M.-Y. Xie, D. Rogalla, H.-W. Becker, K. Lorenz, S. Ruffenach, M. Moret, and O. Briot, Phys. Status Solidi A 208, 1179 (2011).

${ }^{11}$ J. S. Speck, Mater. Res. Soc. Bull. 34, 309 (2009).

${ }^{12}$ C.-H. Liang, Z. H. Sun, C. L. Hsiao, Z. M. Hsu, L.W. Tu, J.-Y. Lin, L. C. Chen, J. H. Chen, Y. F. Chen, and C. T. Wu, Appl. Phys. Lett. 90, 172101 (2007).

${ }^{13}$ C. L. Hsiao, T. W. Liu, C. T. Wu, H. C. Hsu, G. M. Hsu, L. C. Chen, W. Y. Shiao, C. C. Yang, A. Gällström, P.-O. Holtz, C. C. Chen, and K. H. Chen, Appl. Phys. Lett. 92, 111914 (2008).

${ }^{14}$ Y. Nanishi, Y. Saito, T. Yamaguchi, M. Hori, F. Matsuda, T. Araki, A. Suzuki, and T. Miyajima, Phys. Status Solidi A 200, 202 (2003).

${ }^{15}$ Y. Kumagai, A. Tsuyuguchi, H. Naoi, H. Na, and Y. Nanishi, Phys. Status Solidi B 243, 1468 (2006).

${ }^{16}$ Y. Nanishi, T. Araki, and T. Yamaguchi, in Indium Nitride and Related Alloys, edited by T. D. Veal, C. F. McConville, and W. J. Schaff (CRC Press, Boca Raton, 2009), p. 28.

${ }^{17}$ H. Lu, W. J. Schaff, J. Hwang, H. Wu, G. Koley, and L. F. Eastman, Appl. Phys. Lett. 79, 1489 (2001).

${ }^{18}$ H. Lu, W. J. Schaff, L. F. Eastmann, J. Wu, W. Walukiewicz, V. Cimalla, and O. Ambacher, Appl. Phys. Lett. 83, 1136 (2003).

${ }^{19}$ V. Darakchieva, M. Schubert, T. Hofmann, B. Monemar, C. L. Hsiao, T. W. Liu, L. C. Chen, W. J. Schaff, Y. Takagi, and Y. Nanishi, Appl. Phys. Lett. 95, 202103 (2009). 
${ }^{20}$ V. Darakchieva, M. Y. Xie, N. Franco, F. Giuliani, B. Nunes, E. Alves, C. L. Hsiao, L. C. Chen, T. Yamaguchi, Y. Takagi, K. Kawashima, and Y. Nanishi, J. Appl. Phys. 108, 073529 (2010).

${ }^{21}$ K. Lorenz, S. M. C. Miranda, N. P. Barradas, E. Alves, Y. Nanishi, W. J. Schaff, L. W. Tu, and V. Darakchieva, AIP Conf. Proc. 1336, 310 (2011).

${ }^{22}$ N. P. Barradas, C. Jeynes, and R. P. Webb, Appl. Phys. Lett.71, 291 (1997).
${ }^{23}$ S. C. Cruz, S. Keller, T. E. Matesand, U. K. Mishra, and S. P. DenBaars, J. Cryst. Growth 311, 38117 (2009).

${ }^{24}$ F. González-Posada Flores, A. Redondo-Cubero, R. Gago, A. Bengoechea, A. Jiménez, D. Grambole, A. F. Brana, and E. Munoz, J. Phys. D: Appl. Phys. 42, 055406 (2009).

${ }^{25}$ A. Terentjevs, G. Cicero, and A. Catellani, J. Phys. Chem. C 113, 11323 (2009). 